Conference Proceedings Paper - 1st International Electronic Conference on Molecular Science: Cell Signaling, Survival and Growth

\title{
Interferon Alpha Induces the Apoptosis of Cervical Cancer HeLa Cells by Activating Both the Intrinsic Mitochondrial Pathway and ER Stress-Induced Pathway
}

\author{
Wei-Ye Shi, Li Liu * \\ Department of Microbiology, Institute of Basic Medical Sciences, Chinese Academy of Medical \\ Sciences \& Peking Union Medical College, Beijing 100005, China; E-Mails: feiwudeyezi@126.com \\ * Author to whom correspondence should be addressed; E-Mail: 1liu@pumc.edu.cn; \\ Tel.: +86-10-6915-6454; Fax: +86-10-6523-3768.
}

Received: 29 September 2015 / Published: 15 October 2015

\begin{abstract}
The interferon alpha (IFN- $\alpha$ ) has been used for treatment of various malignancies such as hepatocellular carcinoma (HCC), malignant melanoma and renal cell cancer (RCC), and has been shown to promote the apoptosis and inhibit the growth of several tumor cell types. However, the effect of IFN- $\alpha$ on cervical cancer is completely unknown. In this study, HeLa cells were used as a testing model for the treatment of IFN- $\alpha$ on cervical cancer. The results indicate that IFN- $\alpha$ could markedly inhibit the proliferation and induce the apoptosis of HeLa cells. The activation of caspase 3, the up-regulation of Bim and the cleaved PARP1, the down-regulation of $\mathrm{Bcl}-\mathrm{xL}$ as well as the release of cytochrome $\mathrm{C}$ from mitochondria to cytosol were significantly induced upon IFN- $\alpha$ treatment. In addition, caspase 4 which is implicated in ER stress-induced apoptosis was cleaved with IFN- $\alpha$ treatment. Knockdown of caspase 4 by siRNA markedly reduced the cell apoptosis rate, but not affected the mitochondrial apoptotic pathway. Moreover, no significant changes on the expression of caspase 8 , caspase 10 , Fas/Fas-L were observed upon IFN- $\alpha$ treatments, indicating the apoptosis caused by IFN- $\alpha$ may be independent of extrinsic apoptotic pathway. These findings suggest that IFN- $\alpha$ may possesses the capacity of anti cervical cancer by mainly activating both the intrinsic mitochondrial pathway and ER stress-induced pathway.
\end{abstract}

Keywords: IFN- $\alpha$; apoptosis; HeLa cell; Intrinsic Mitochondrial pathway; ER Stress 


\section{Introduction}

Human interferon alpha (IFN- $\alpha$ ) is one kind of the type I interferons (IFNs) which are a large subgroup of interferon cytokines that are widely known to regulate the immune system and induce potent innate immune response against viral infection $[1,2]$. Due to its immunotherapeutical effect on viral infection, IFN- $\alpha$ has been made synthetically as medication drugs in different types such as the recombinant interferon alpha-1, the pegylated interferon alpha-2a and pegylated interferon alpha- $2 b$ [3].

In recent years, IFN- $\alpha$ has been found to exert a variety of other biological effects includes the inhibition of cell proliferation, the induction of cell apoptosis, and the suppression of oncogene expression and so on [4-10]. Therefore, it has been increasingly used in clinical to treat a wide range of malignancies, such as hepatocellular carcinoma (HCC), malignant melanoma and renal cell cancer (RCC) [11-15]. However, IFN- $\alpha$ has been rarely used in the treatment of cervical cancer either alone or in combination with other agents. Cervical cancer is a cancer arising from the cervix and is one of the major threatens to women's health. There is no effective way to cure cervical cancer at present [16]. Therefore, finding a novel and effective treatment on this disease will be the direction of scientist make efforts.

Apoptosis is a basic physiological response of the body to maintain homeostasis which involves many gene products and cell cytokines. Through apoptosis, the body can eliminate damaged, aged and mutated cells to maintain the normal function and homeostasis of various organs and systems [17-20]. The three main apoptotic pathways include the mitochondria-induced intrinsic apoptotic pathway, ER stressinduced apoptotic pathway and dead receptor-induced extrinsic apoptotic pathway. Apoptosis is primarily executed by a family of proteases known as the caspases (cysteinyl, aspartate-specific proteases), among them the activation of caspase- 3 is the hallmark of apoptosis. The activation of other type of caspases represents different apoptosis pathways [21-24]. For example, the proximity-induced activations of caspases 8 and 10 occurs in the extrinsic apoptotic pathway release the respective activated caspase molecules into the cytoplasm and then cleave and subsequently stimulate the effectors (caspases 3, 6, and 7) which ultimately execute apoptosis [25].

In this study, HeLa cells were used as a testing model for the treatment of IFN- $\alpha$ on cervical cancer. The influence of IFN- $\alpha$ on HeLa cells proliferation and apoptosis was evaluated by various standard apoptotic analysis. We attempt to clarify the mechanisms and the definite apoptotic pathways induced by IFN- $\alpha$, and lay theoretical foundation for the subsequent animal experiments and clinical application.

\section{Results and Discussion}

\subsection{IFN- $\alpha$ Inhibits the Proliferation of HeLa Cells}

Since IFN- $\alpha$ has been reported to inhibit cell proliferation and induce cell apoptosis in certain tumor types, it might be true that IFN- $\alpha$ also possesses antiproliferative and proapoptosis effects on HeLa cells. To test this assumption, glucose/lactate assay in cell culture medium and MTT assay were firstly performed to detect the HeLa cell growth ability affected by IFN- $\alpha$ on different doses. The culture medium and whole cell lysates were collected at different time points. Due to the growing number of cells will lead to increasing glucose uptake and lactate production, the content of glucose in culture medium will reduced while the content of lactate will upraise. Figure 1a clearly shows that the glucose level increased and lactate level decreased along with the increasing doses of IFN- $\alpha$, indicating that the 
proliferation potentials of HeLa cells were markedly inhibited. Consistently, numbers of viable cells were significantly reduced as the doses of IFN- $\alpha$ increased after 48 and $72 \mathrm{~h}$ treatments as demonstrated in MTT assay (Figure 1b).

a

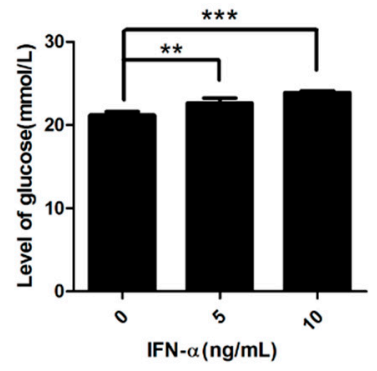

$12 \mathrm{~h}$

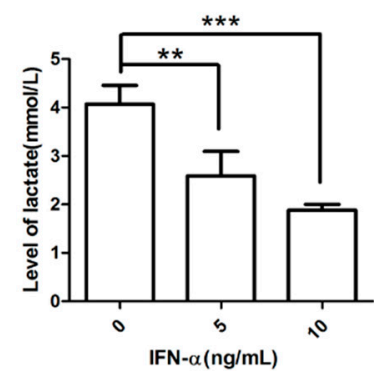

$12 \mathrm{~h}$

b

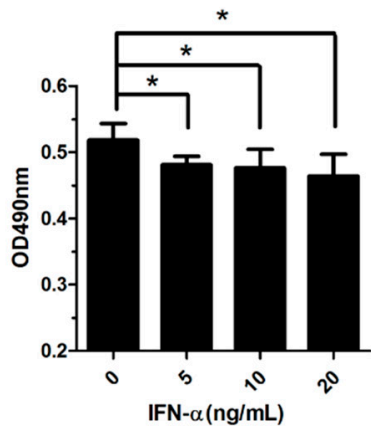

$48 \mathrm{~h}$

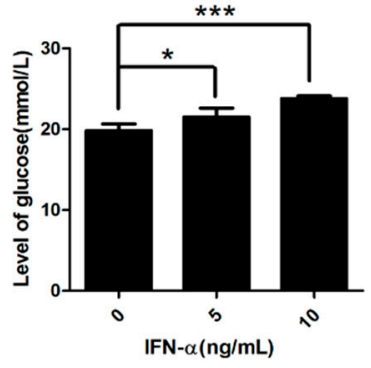

$24 \mathrm{~h}$

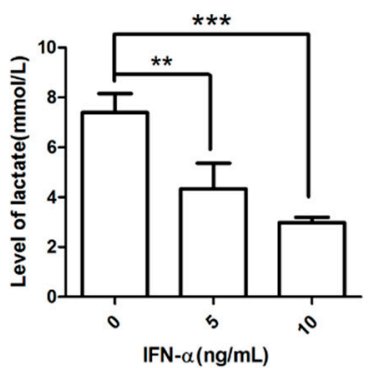

$24 \mathrm{~h}$

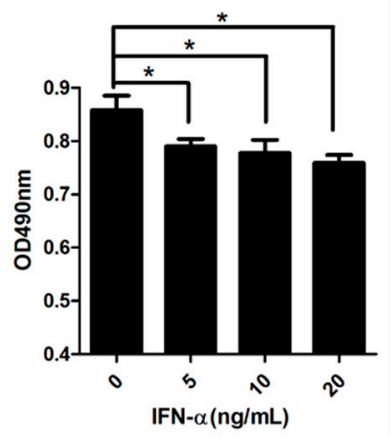

$72 \mathrm{~h}$

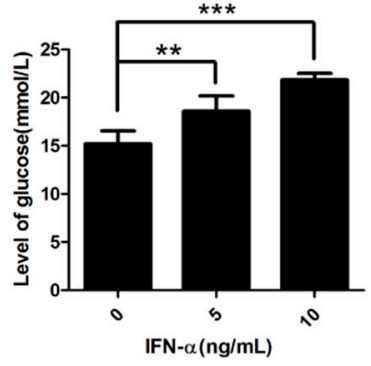

$48 \mathrm{~h}$

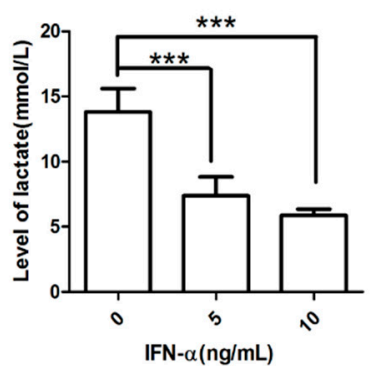

$48 \mathrm{~h}$

Figure 1. Treatment with IFN- $\alpha$ inhibits the proliferation of human cervical cancer cell line HeLa cells. (a) Glucose and lactate levels in cell culture medium. HeLa cells were treated with increased doses $(0,5$ and $10 \mathrm{ng} / \mathrm{mL})$ of IFN- $\alpha$ for 12,24 and $48 \mathrm{~h}$. The detection of glucose and lactate levels in cell culture medium was performed with EKF Biosen C_line. Each value represented as mean \pm SD from four independent treatments. Statistic analysis was performed with student's $t$ test. Statistical difference was considered to be significant if $\mathrm{p}<0.05$; (b) Detection of cell proliferation. After treatment with increased doses $(0,5,10$ and $20 \mathrm{ng} / \mathrm{mL}$ ) of IFN- $\alpha$ for 48 and $72 \mathrm{~h}$, the treated HeLa cells were collected and assayed by MTT. The reaction products were measured at $490 \mathrm{~nm}$ with a plate reader. Each value represented as mean \pm SD from four independent treatments. Statistic analysis was performed with student's $t$ test. Statistical difference was considered to be significant if $p<$ 0.05 . 


\subsection{IFN- $\alpha$ Induces the Apoptosis of HeLa Cells}

Inhibition of cell proliferation is often accompanied by the occurrence of cell apoptosis. To this end, HeLa cells were treated with IFN- $\alpha$. After $48 \mathrm{~h}$ treatment, the cells were collected and subjected to Annexin V and PI double staining. Subsequent flow cytometric analysis showed a marked increase in the population of Annexin V+/PI- cells in responding to higher dose IFN- $\alpha$ delivery (Figure 2a). Statistical analysis showed that higher dose delivery of IFN- $\alpha$ significantly increased the population of early apoptotic cells (Figure 2b). To further define the optimal treatment dose of IFN- $\alpha$, HeLa cells were treated with seven increased doses of IFN- $\alpha$ for $48 \mathrm{~h}$, cell apoptosis was detected in the same way as Figure $2 \mathrm{a}$ and $2 \mathrm{~b}$. Finally, the dose $0,5,10 \mathrm{ng} / \mathrm{mL}$ were selected as the optimal treatment dose and used for subsequent experiments (Figure 2c).

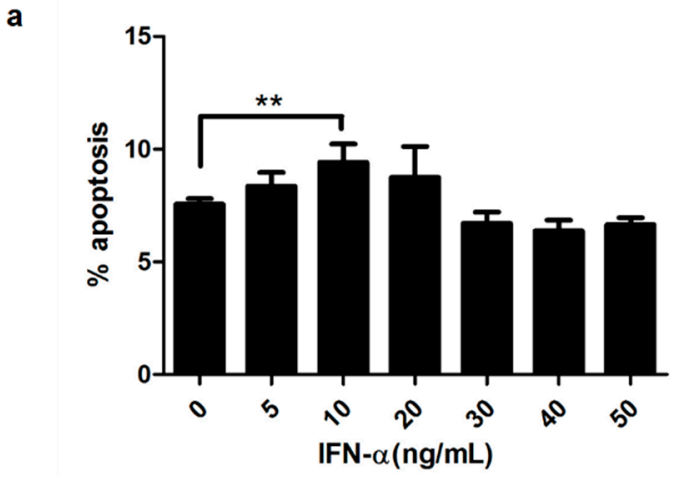

b

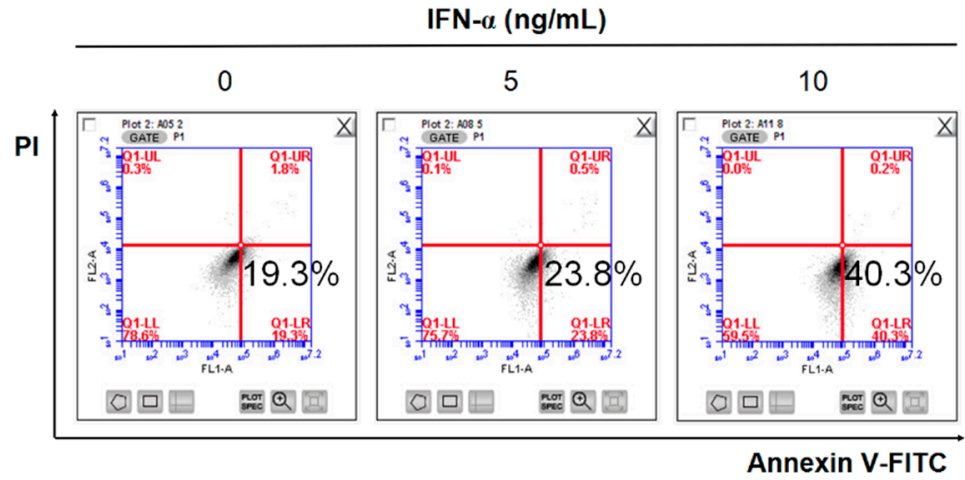

c

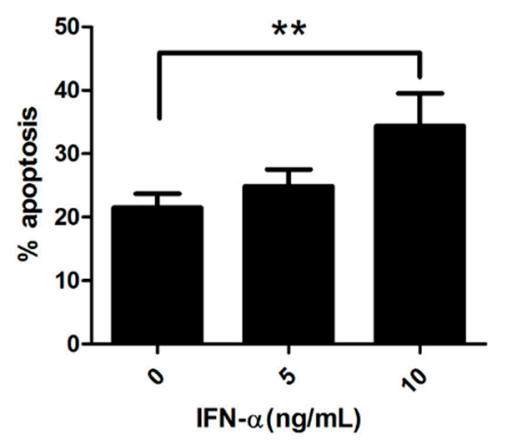

Figure 2. Treatment with IFN- $\alpha$ accelerates the apoptosis of HeLa cells. (a) Determination of validated dose of IFN- $\alpha$ for inducing HeLa cells apoptosis. HeLa cells were treated with seven increased doses of IFN- $\alpha$ for $48 \mathrm{~h}$, cell apoptosis was detected in the same way as described below. Each value represented as mean \pm SD from four independent treatments. Statistic analysis was performed with student's $t$ test. Statistical difference was considered significant if $\mathrm{p}<0.05$; (b) Detection of cell apoptosis in IFN- $\alpha$ treated HeLa cells seeded on a 12 well culture plate was performed with Annexin V/Propidium iodide (PI) double staining followed by flow cytometric analysis; (c) Quantitation of early apoptotic cells treated by IFN- $\alpha$. The treated HeLa cells were stained and analyzed as described in (b). Annexin V+/PIcells were counted. Each value represented as mean $\pm \mathrm{SD}$ from three independent treatments. Statistic analysis was performed with student's $t$ test. Statistical difference was considered significant if $\mathrm{p}<0.05$. 


\subsection{The Mitochondrial Apoptotic Pathway is Activated by IFN- $\alpha$ Treatment}

First, we intend to detect whether or not IFN- $\alpha$ induced cell apoptosis is associated with the activation of intrinsic mitochondria pathway. To this end, cell lysates prepared from IFN- $\alpha$ treated HeLa cells were probed with anti-Bim, anti-Bcl-xL, anti-procaspase 3, anti-cytochrome $\mathrm{C}$ and anti-cleaved PARP-1 antibodies. Bcl-xL belongs to BCL2 family and exerts its anti-apoptotic function by preventing the oligomerization of Bax/Bak proteins at the mitochondrial outer membrane, while Bim who also belongs to BCL2 family has the opposite function to Bcl-xL. Oligomeric Bax/Bak proteins insert to the outer mitochondrial membrane, causing the alterations of membrane permeability and release of cytochrome $\mathrm{C}$, eventually, caspase 3 is activated which leads to cell apoptosis. Indeed, treatment of IFN- $\alpha$ in HeLa cells inhibited the expression levels of Bcl-xL proteins while promoted the expression levels of Bim in a dose-dependent manner (Figure 3a). It also markedly induced the release of cytochrome $\mathrm{C}$ and activation of the executioner caspase 3. In addition, a marked increase in the production of the cleaved PARP-1 was also detected as the doses of IFN- $\alpha$ increased (Figure 3a).

To further confirm that the release of cytochrome $\mathrm{C}$ is indeed from mitochondrial, mitochondrial and cytoplasmic fractions were separated after $48 \mathrm{~h}$ treatment using Mitochondria Isolation Kit. Then, cytochrome $\mathrm{C}$ proteins in both of mitochondria and cytoplasm were detected by western blot analysis. Figure $3 \mathrm{~b}$ demonstrates that cytochrome $\mathrm{C}$ proteins in mitochondria decreased while proteins in cytoplasm increased. Thus, the data strongly indicates that IFN- $\alpha$ mediated apoptosis is associated with the activation of intrinsic mitochondrial pathway in HeLa cells.

a

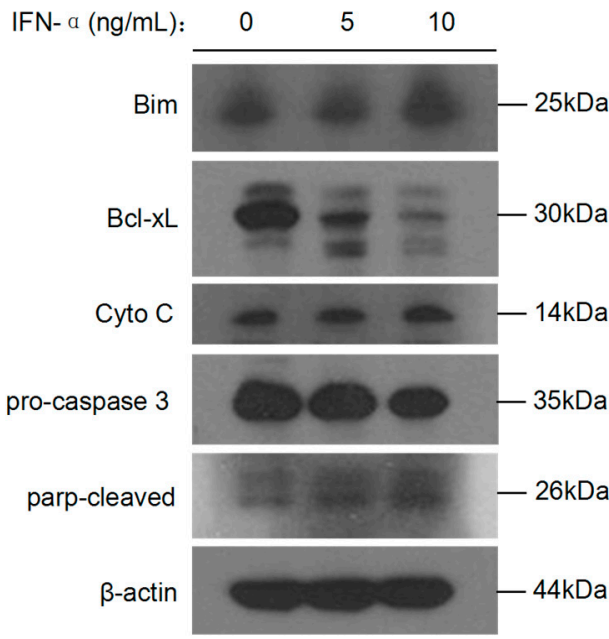

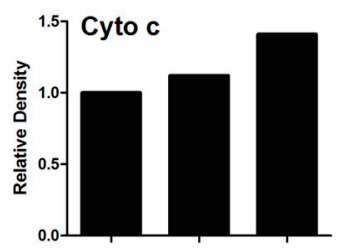
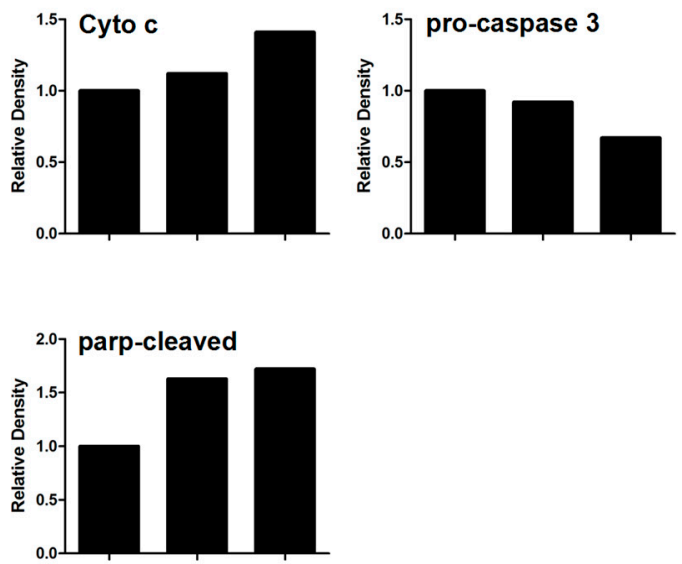

b

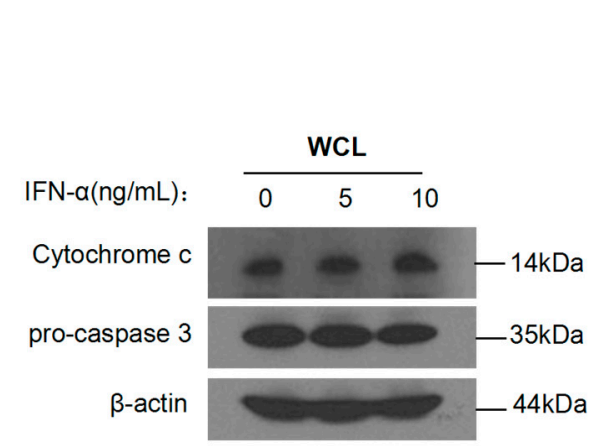

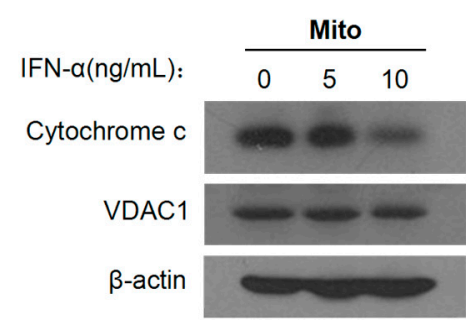
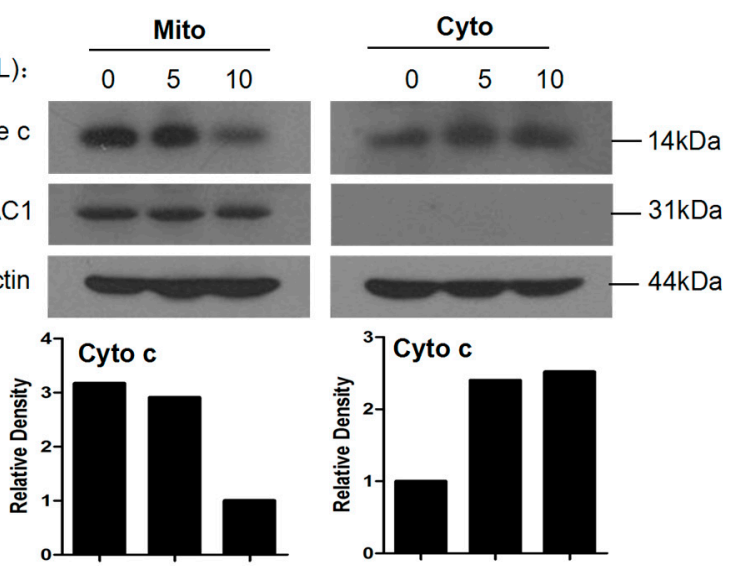
Figure 3. IFN- $\alpha$ mediated cell apoptosis in HeLa cells is associated with mitochrondria mediated intrinsic pathway. (a) The whole cell lysates prepared from IFN- $\alpha$ treated HeLa cells after $48 \mathrm{~h}$ treatment were probed with anti-Bim, anti-Bcl-xL, anti-procaspase 3, anticytochrome $\mathrm{C}$ and anti-cleaved PARP-1 antibodies and analyzed by Western blot. $\beta$-actin gene expression was served as internal control; (b) Mitochondrial and cytoplasmic proteins were seperated after $48 \mathrm{~h}$ treatment using Mitochondria Isolation Kit. The whole cell lysates were probed with anti-cytochrome $\mathrm{C}$ and anti-procaspase 3 antibodies, the mitochondrial and cytoplasmic protein lysates were probed with anti-cytochrome $\mathrm{C}$ antibody and analyzed by Western blot. $\beta$-actin gene expression was served as internal control, VDAC1 was an mitochondrial marker. In both (a) and (b), the relative density of individual band was calculated based on the expression of $\beta$-actin by using the Image $J$ program.

\subsection{ER Stress-Induced Apoptotic Pathway but not Extrinsic Apoptotic Pathway Is Also Activated by} IFN- $\alpha$ Treatment

In addition to the intrinsic apoptotic pathway, the extrinsic and ER stress-induced apoptotic pathways may also be activated. As described above, the activation of caspases 8/10 occurs in the extrinsic apoptotic pathway. Caspase 4 in human (caspase 12 in mouse) is specifically localized on the cytoplasmic side (outer membrane) of the ER and is thought to play a role in ER stress-mediated cell death $[26,27]$. Figure $4 \mathrm{a}$ demonstrated shows that no significant changes on the expression of caspases $8 / 10$ proteins could been detected (Figure $4 \mathrm{a}$ ). However, the activation of caspase 4 was induced as the doses of IFN- $\alpha$ increased (Figure $4 b$ ), indicating that ER stress-induced apoptotic pathway may also contribute to IFN- $\alpha$ mediated cell apoptosis in HeLa cells.

To further verify the result, caspase 4 siRNA was constructed to knowdown the expression of endogenous caspase 4 . Figure $5 \mathrm{a}$ and $5 \mathrm{~b}$ shows notable interference effect on RNA level and protein level respectively. Then, HeLa cells were treated with increased doses of IFN- $\alpha$, and at the same time transfected with control siRNA or caspase 4 siRNA for $48 \mathrm{~h}$. Cell apoptosis assay was performed as described above. A marked increase in the population of apoptotic cells appeared in responding to higher dose IFN- $\alpha$ treatment, whereas, it decreased significantly when treated both of IFN- $\alpha$ and caspase 4 siRNA (Figure 5c).

All these data preliminarily articulates that ER stress-induced apoptotic pathway but not extrinsic apoptotic pathway is also activated by IFN- $\alpha$ treatment. 
a

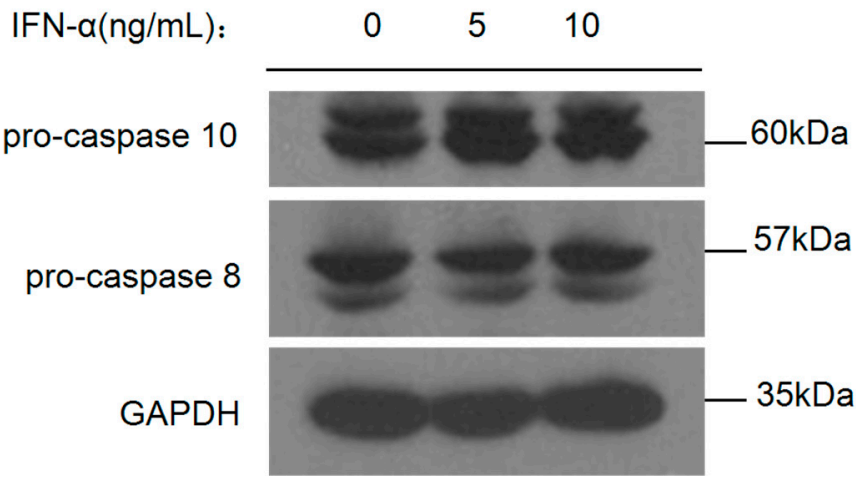

b

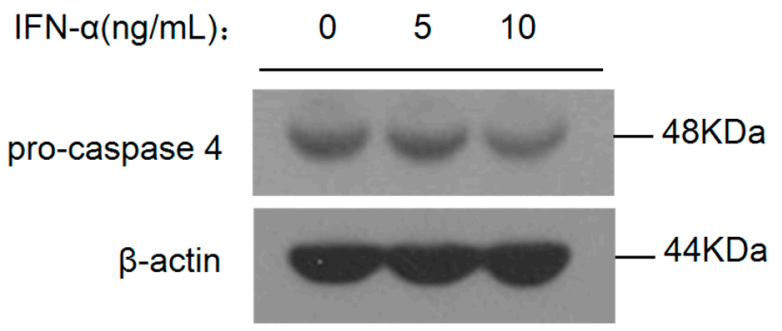

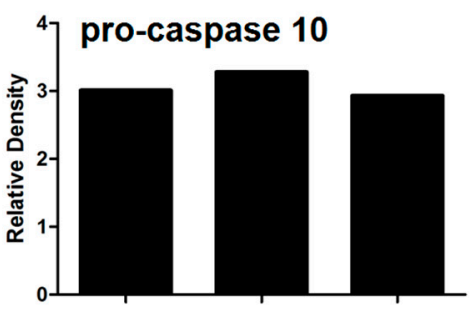
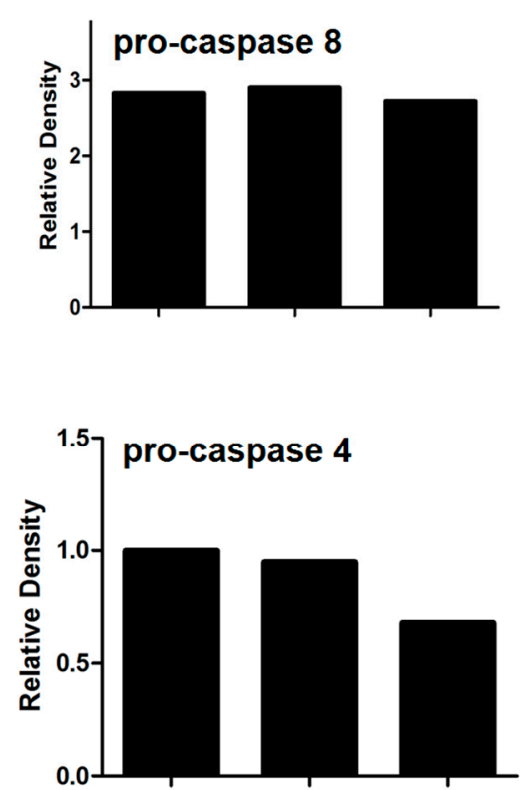

Figure 4. IFN- $\alpha$ mediated cell apoptosis in HeLa cells also involves ER stress-induced apoptotic pathway. (a) The whole cell lysates prepared from IFN- $\alpha$ treated HeLa cells after $48 \mathrm{~h}$ treatment were probed with anti-caspase 8 and 10 antibodies and analyzed by Western blot. GAPDH gene expression was served as internal control; (b) Whole cell lysates were probed with anti-caspase 4 antibody and analyzed by Western blot. $\beta$-actin gene expression was served as internal control, and the relative density of individual band was calculated based on the expression of $\beta$-actin by using the Image J program. 


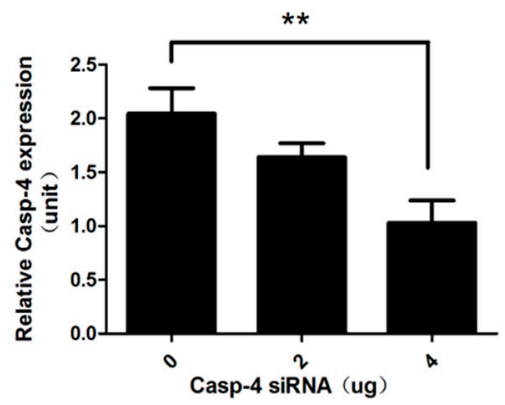

b

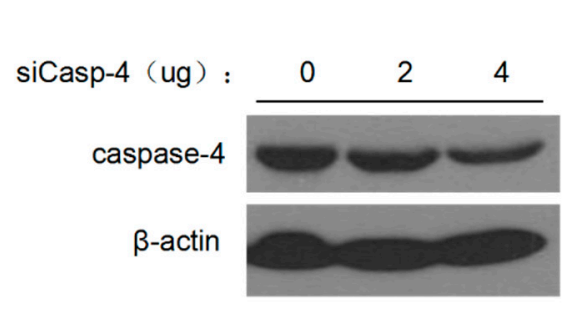

WB

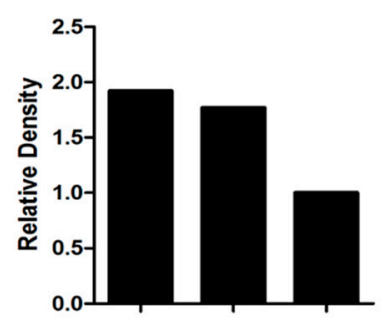

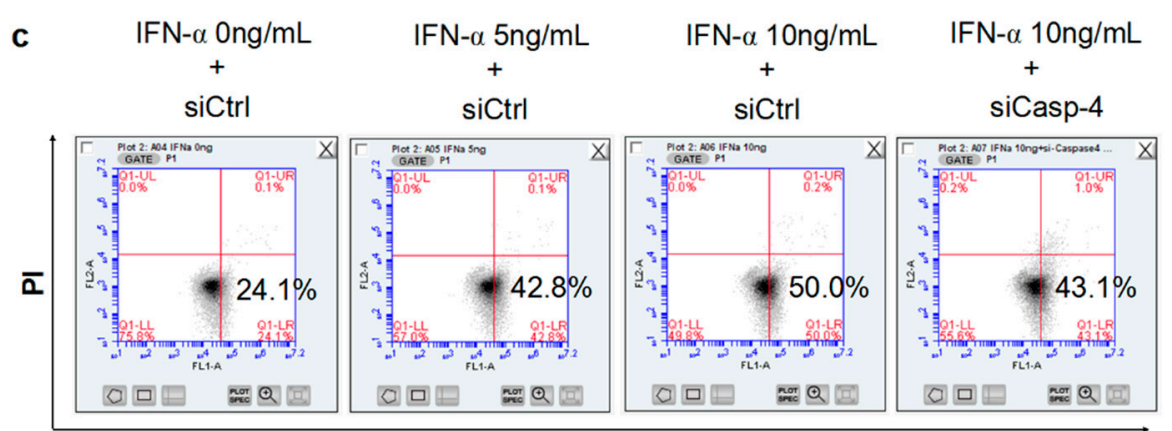

Annexin V-FITC

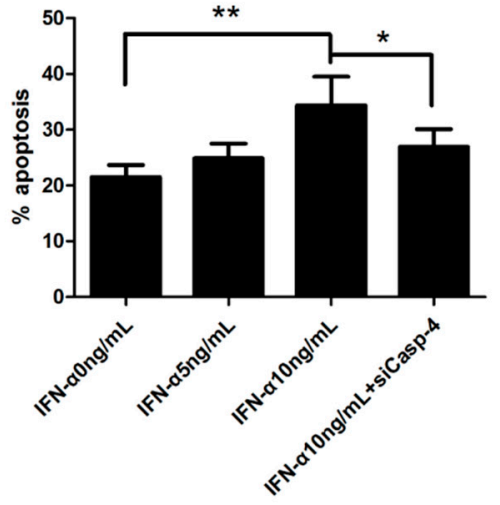

Figure 5. Knockdown of caspase 4 reduces HeLa cell apoptosis mediated by IFN- $\alpha$ treatment. (a) and (b) The inhibitory effect of caspase 4 siRNA on endogenous caspase 4 expression. HeLa cells were transfected with increased doses $(0,2$ and $4 \mu \mathrm{g})$ of caspase 4 siRNA for 48h. Real-time PCR (qPCR) analysis with whole HeLa cell RNAs in (a) and Western Blot analysis with whole HeLa cell lysates in (b) were then performed. $\beta$-actin gene expression was served as internal control. (c) HeLa cells were treated with increased doses of IFN- $\alpha$ and transfected with control siRNA or caspase 4 siRNA at the same time for $48 \mathrm{~h}$. Cell apoptosis assay was performed with Annexin V/Propidium iodide (PI) double staining followed by flow cytometric analysis. Annexin V+/PI- cells were counted. Each value represented as mean $\pm \mathrm{SD}$ from three independent treatments. Statistic analysis was performed with student's $t$ test. Statistical difference was considered significant if $\mathrm{p}<0.05$.

\subsection{The ER Stress-Induced Apoptotic Pathway and the Mitochondrial Apoptotic Pathway Are Independently Induced by IFN- $\alpha$}

To investigate whether ER stress-induced apoptotic pathway has an effect on the mitochondrial apoptotic pathway in the HeLa cell death mediated by IFN- $\alpha$, HeLa cells were treated with or without IFN- $\alpha$, and at the same time transfected with control siRNA or caspase 4 siRNA for $48 \mathrm{~h}$. Part of the cells were collected to carry out apoptosis assay with Annexin V/Propidium iodide (PI) double staining followed by flow cytometric analysis. The remaining cells were used to detect key proteins in mitochondrial apoptotic pathway by Western blotting. Figure $6 \mathrm{a}$ demonstrates the same conclusion as to Figure 5c. Despite the fact that knockdown of caspase 4 markedly reduced cell apoptosis, it scarcely affactted the inhibition on Bcl-xL, release of cytochrome $\mathrm{C}$ and activation of caspase 3 (Figure 6a). 
Collectively, the data indicates that ER stress-induced apoptotic pathway and mitochondrial intrinsic apoptotic pathway maybe independent in IFN- $\alpha$ mediated HeLa cell apoptosis model.

a

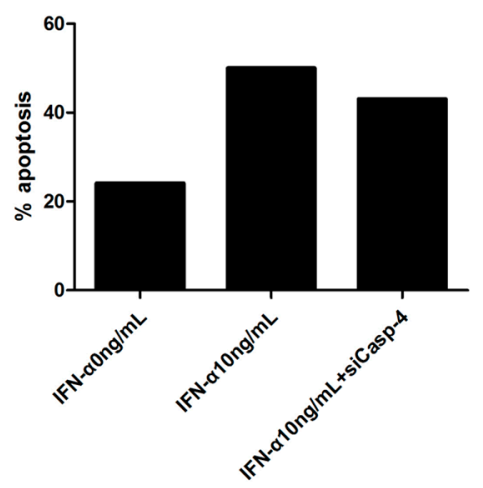

b
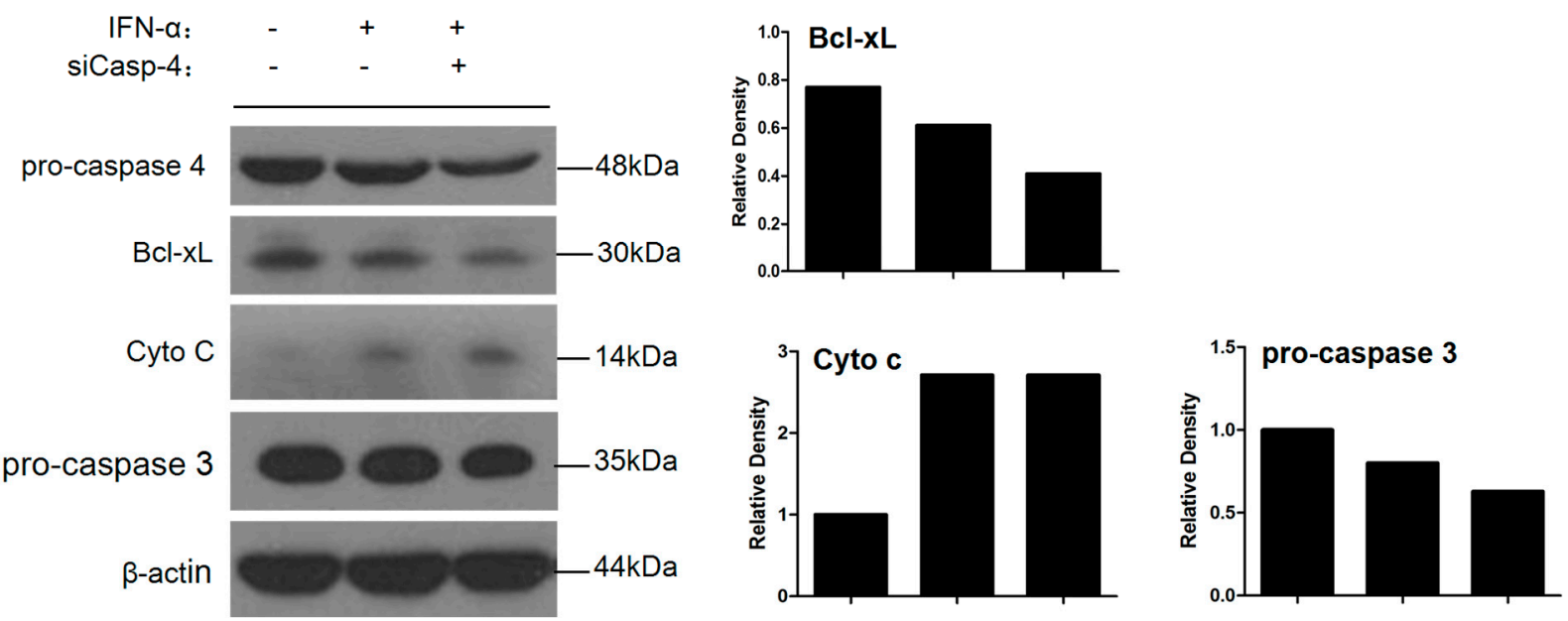

Figure 6. Inhibiting caspase 4 expression does not affect the mitochondrial apoptotic pathway. (a) Detection of cell apoptosis. HeLa cells were treated with or without IFN- $\alpha$ and transfected with control or caspase 4 siRNA at the same time for $48 \mathrm{~h}$. Cell apoptosis was performed as described above; (b) The whole cell lysates were probed with anti-procaspase 4, anti-Bcl-xL, anti-cytochrome $\mathrm{C}$ and anti-procaspase 3 antibodies and analyzed by Western blot. $\beta$-actin gene expression was served as internal control, and the relative density of individual band was calculated based on the expression of $\beta$-actin by using the Image $\mathbf{J}$ program.

\section{Experimental Section}

\subsection{Cell Lines, Chemicals and Reagents}

Human cervical cancer cell line (HeLa) was derived from the Cell Culture Center of Institute of Basic Medical Sciences, Chinese Academy of Medical Sciences (Beijing, China). Rabbit anti-caspase 3, rabbit anti Bim, rabbit anti Bcl-xL, rabbit anti cytochrome $\mathrm{C}$, rabbit anti $\beta$-actin were purchased from Santa Cruz Biotechnology (Santa Cruz, CA, USA). Rabbit anti-cleaved PARP1 was purchased from Epitomics Inc. (Burlingame, CA, USA). Mouse anti-caspase 8, rabbit anti-caspase 10 and rabbit anti-caspase 4 were purchased from Bioworld Technology Inc. (Bioworld, CA, USA). The peroxidase-conjugated secondary antibodies were from Zhongshan Biotechnology (Beijing, China). The Recombinant Human Interferon-Alpha was purchased from ProSpec-Tany TechnoGene Ltd. Caspase-4 siRNA: 5- 
gatccgcctcagtctgaaggacaactcgagttgtccttcagactgaggca-3 (antisense).

\subsection{Glucose/Lactate Level Assay}

Glucose / Lactate level in cell culture medium was detected by EKF Biosen C_line (Beijing Neckar Healthcare Co. Ltd.). Equal amounts of cells were cultured to $80 \%$ confluency in 12 well plate. After $48 \mathrm{~h}$ treatment with IFN- $\alpha, 10 \mathrm{uL}$ culture medium from each well was added into the corresponding test solution. Detection was performed using EKF Biosen C_line instrument.

\subsection{Cell Proliferation Assay by MTT}

Cell proliferation potential was evaluated by MTT assay. Briefly, equal amount of cells were cultured in a 96-well plate and treated with IFN $\alpha$ for 48 or 72 hours before testing. MTT solution was added into each well. After $3 \mathrm{~h}$ incubation, the absorbance at $490 \mathrm{~nm}$ was measured using a microplate reader.

\subsection{Flow Cytometric Analysis}

Cell apoptosis was detected by Annexin V-FITC apoptosis detection kit ( Biotool, Beijing, China). After $48 \mathrm{~h}$ treatment, cells were released and washed with pre-cooled $1 \times$ PBS. Then the cell pellet was resuspended into $50 \mu \mathrm{l}$ binding buffer followed by adding $5 \mu \mathrm{l}$ Annexin V-FITC and $5 \mu$ Propidium Iodide (PI). Then the cell suspension was incubated away from light for $15 \mathrm{~min}$ at room temperature. Another $150 \mu \mathrm{l}$ binding buffer was added into the mixture before flow cytometric analysis by Accuri C6 (BD Biosciences, San Jose, CA, USA).

\subsection{Real time PCR (qRT-PCR)}

Total RNAs were extracted from the cultured cells with TRIzol (Invitrogen, Carlsbad, CA, USA). The primers used in the qRT-PCR reactions were listed in Table 1. $100 \mathrm{ng}$ of total RNAs was subjected to qRT-PCR analysis using One Step SYBR PrimeScript RT-PCR Kit II (Perfect Real Time, Takara Biotechnology, Dalian, China). The realtime qRT-PCR was carried out with iQ7 real time PCR detection system (Bio-Rad Laboratories, Hercules, CA, USA) at the following conditions: $42{ }^{\circ} \mathrm{C}$ for 5 min and 95 ${ }^{\circ} \mathrm{C}$ for $10 \mathrm{~s} ; 95{ }^{\circ} \mathrm{C}$ for $5 \mathrm{~s}$ and $60{ }^{\circ} \mathrm{C}$ for $30 \mathrm{~s}$ and repeated for 40 cycles. The dissociation of the reaction products was from $55^{\circ} \mathrm{C}$ to $95{ }^{\circ} \mathrm{C}$ as the temperature rose at $0.2^{\circ} \mathrm{C}$ per $10 \mathrm{~s}$. The level of $\beta$-actin gene expression was served as internal control.

Table 1. Primers used in qRT-PCR analysis.

\begin{tabular}{ccccc}
\hline Gene Name & Genbank ID & $\begin{array}{c}\text { Forward Primer } \\
\left(\mathbf{5}^{\prime} \rightarrow \mathbf{3}^{\prime}\right)\end{array}$ & Reverse Primer $\left(\mathbf{5}^{\prime} \rightarrow \mathbf{3}^{\prime}\right)$ & Size of Product(bp) \\
\hline$\beta$-actin & BC009275 & tccatcatgaagtgtgacgt & ctcaggaggagcaatgatct & 161 \\
Caspase 4 & EF636667 & ttgctttctgctcttcaacg & gtgtgatgaagatagagcccatt & 72 \\
\hline
\end{tabular}

\subsection{Western Blot Analysis}

The treated cells were lysed with gentle rotation in a lysis buffer (1\% NP-40, $50 \mathrm{mM}$ Tris-HCl (pH 7.5), $120 \mathrm{mM} \mathrm{NaCl}, 200 \mu \mathrm{M} \mathrm{NaVO} 4,1 \mu \mathrm{g} / \mathrm{ml}$ leupeptin, $1 \mu \mathrm{g} / \mathrm{ml}$ aprotinin, and $1 \mu \mathrm{M}$ PMSF). Cell 
lysate for each sample was resolved on 12\% SDS-PAGE followed by blotting onto Hybond nitrocelluar membrane (Amersham Biosciences, Freiburg, Germany). The transferred membrane was then probed with primary antibodies followed by relevant secondary antibodies conjugated to horseradish peroxidase. Detection was enhanced by chemiluminescence (Santa Cruz Biotechnology, Santa Cruz, CA, USA).

\subsection{Statistical Analysis}

All values were calculated as mean \pm standard deviation (SD) from four independent experiments. The statistical difference between the assayed group and the standard group was subject to student' $\mathrm{s} t$ test (two-tailed, unpaired). The calculated difference was considered significant as the $p$ value $<0.05$ or $<0.01$.

\section{Conclusions}

In the current study, HeLa cells were used as a testing model for the treatment of IFN- $\alpha$ on cervical cancer. We found that IFN- $\alpha$ could markedly inhibit the proliferation and induce cell apoptosis in HeLa cells. IFN- $\alpha$ activates both the intrinsic mitochondrial pathway and ER stress-induced pathway independently in HeLa cells. Our results highlight a previously unrecognized role of IFN- $\alpha$ on HeLa cells and may provide a new train of thought for future cervical cancer therapy.

\section{Acknowledgments}

This research was supported by National Natural Science Foundation of China (grant No. 30871283 and 81171944).

\section{Author Contributions}

LL conceived and designed the study. WYS performed the experiments. All authors read and approved the manuscript.

\section{Conflicts of Interest}

The authors declare no conflict of interest.

\section{References and Notes}

1. McNab, F.; Mayer-Barber, K.; Sher, A.; Wack, A.; O'Garra, A., Type I interferons in infectious disease. Nature reviews. Immunology 2015, 15, (2), 87-103.

2. Zitvogel, L.; Galluzzi, L.; Kepp, O.; Smyth, M. J.; Kroemer, G., Type I interferons in anticancer immunity. Nature reviews. Immunology 2015, 15, (7), 405-14.

3. Escudier, B.; Lassau, N.; Angevin, E.; Soria, J. C.; Chami, L.; Lamuraglia, M.; Zafarana, E.; Landreau, V.; Schwartz, B.; Brendel, E.; Armand, J. P.; Robert, C., Phase I trial of sorafenib in combination with IFN alpha-2a in patients with unresectable and/or metastatic renal cell carcinoma or malignant melanoma. Clin Cancer Res 2007, 13, (6), 1801-1809. 
4. Bake, V.; Roesler, S.; Eckhardt, I.; Belz, K.; Fulda, S., Synergistic interaction of Smac mimetic and IFN alpha to trigger apoptosis in acute myeloid leukemia cells. Cancer Lett 2014, 355, (2), 224231.

5. Manna, S. K.; Mukhopadhyay, A.; Aggarwal, B. B., IFN-alpha suppresses activation of nuclear transcription factors NF-kappa B and activator protein 1 and potentiates TNF-induced apoptosis. Journal of immunology 2000, 165, (9), 4927-34.

6. Omori, R.; Eguchi, J.; Hiroishi, K.; Ishii, S.; Hiraide, A.; Sakaki, M.; Doi, H.; Kajiwara, A.; Ito, T.; Kogo, M.; Imawari, M., Effects of interferon-alpha-transduced tumor cell vaccines and blockade of programmed cell death-1 on the growth of established tumors. Cancer Gene Ther 2012, 19, (9), 637-643.

7. Shigeno, M.; Nako, K.; Ichikawa, T.; Suzuki, K.; Kawakami, A.; Abiru, S.; Miyazoe, S.; Nakagawa, Y.; Ishikawa, H.; Hamasaki, K.; Nakata, K.; Ishii, N.; Eguchi, K., Interferon-alpha sensitizes human hepatoma cells to TRAIL-induced apoptosis through DR5 upregulation and NF-kappa B inactivation. Oncogene 2003, 22, (11), 1653-1662.

8. Yang, B.; Lu, Y.; Zhang, A.; Zhou, A.; Zhang, L.; Zhang, L.; Gao, L.; Zang, Y.; Tang, X.; Sun, L., Doxycycline Induces Apoptosis and Inhibits Proliferation and Invasion of Human Cervical Carcinoma Stem Cells. Plos One 2015, 10, (6), e0129138.

9. Zhao, J.; Wang, M. L.; Li, Z.; Chen, J. X.; Yin, Z. S.; Chang, J.; Gao, D. M.; Wang, S. P., Interferona suppresses invasion and enhances cisplatin-mediated apoptosis and autophagy in human osteosarcoma cells. Oncol Lett 2014, 7, (3), 827-833.

10. Zuo, C. H.; Qiu, X. X.; Liu, N. L.; Yang, D. R.; Xia, M.; Liu, J. S.; Wang, X. H.; Zhu, H. Z.; Xie, H. L.; Dan, H. G.; Li, Q. L.; Wu, Q. F.; Burns, M.; Liu, C., Interferon-alpha and cyclooxygenase-2 inhibitor cooperatively mediates TRAIL-induced apoptosis in hepatocellular carcinoma. Exp Cell Res 2015, 333, (2), 316-326.

11. Gomez-Benito, M.; Balsas, P.; Carvajal-Vergara, X.; Pandiella, A.; Anel, A.; Marzo, I.; Naval, J., Mechanism of apoptosis induced by IFN-alpha in human myeloma cells: role of Jak1 and Bim and potentiation by rapamycin. Cellular signalling 2007, 19, (4), 844-54.

12. Herzer, K.; Hofmann, T. G.; Teufel, A.; Schimanski, C. C.; Moehler, M.; Kanzler, S.; SchulzeBergkamen, H.; Galle, P. R., IFN-alpha-Induced Apoptosis in Hepatocellular Carcinoma Involves Promyelocytic Leukemia Protein and TRAIL Independently of p53. Cancer Res 2009, 69, (3), 855862.

13. Krasagakis, K.; Kruger-Krasagakis, S.; Tzanakakis, G. N.; Darivianaki, K.; Stathopoulos, E. N.; Tosca, A. D., Interferon-alpha inhibits proliferation and induces apoptosis of Merkel cell carcinoma in vitro. Cancer Invest 2008, 26, (6), 562-568.

14. Lesinski, G. B.; Raig, E. T.; Guenterberg, K.; Brown, L.; Go, M. R.; Shah, N. N.; Lewis, A.; Quimper, M.; Hade, E.; Young, G.; Chaudhury, A. R.; Ladner, K. J.; Guttridge, D. C.; Bouchard, P.; Carson, W. E., IFN-alpha and Bortezomib Overcome Bcl-2 and Mcl-1 Overexpression in Melanoma Cells by Stimulating the Extrinsic Pathway of Apoptosis. Cancer Res 2008, 68, (20), 8351-8360.

15. Li, T.; Dong, Z. R.; Guo, Z. Y.; Wang, C. H.; Tang, Z. Y.; Qu, S. F.; Chen, Z. T.; Li, X. W.; Zhi, $\mathrm{X}$. T., Aspirin enhances IFN-alpha-induced growth inhibition and apoptosis of hepatocellular carcinoma via JAK1/STAT1 pathway. Cancer Gene Ther 2013, 20, (6), 366-374. 
16. Larmour, L. I.; Jobling, T. W.; Gargett, C. E., A Review of Current Animal Models for the Study of Cervical Dysplasia and Cervical Carcinoma. International journal of gynecological cancer : official journal of the International Gynecological Cancer Society 2015, 25, (8), 1345-52.

17. Jin, Z. Y.; El-Deiry, W. S., Overview of cell death signaling pathways. Cancer Biol Ther 2005, 4, (2), 139-163.

18. Klener, P.; Andera, L.; Klener, P.; Necas, E.; Zivny, J., Cell death signalling pathways in the pathogenesis and therapy of haematologic malignancies: Overview of therapeutic approaches. Folia Biol-Prague 2006, 52, (4), 119-136.

19. Plati, J.; Bucur, O.; Khosravi-Far, R., Apoptotic cell signaling in cancer progression and therapy. Integr Biol-Uk 2011, 3, (4), 279-296.

20. Yang, Z.; Zhang, X. Q.; Dinney, C. N. P.; Benedict, W. F., Direct cytotoxicity produced by adenoviral-mediated interferon alpha gene transfer in interferon-resistant cancer cells involves ER stress and caspase 4 activation. Cancer Gene Ther 2011, 18, (9), 609-616.

21. Ashkenazi, A., Targeting the extrinsic apoptosis pathway in cancer. Cytokine Growth $F$ R 2008, 19, (3-4), 325-331.

22. Sayers, T. J., Targeting the extrinsic apoptosis signaling pathway for cancer therapy. Cancer Immunol Immun 2011, 60, (8), 1173-1180.

23. Wallach, D.; Kang, T. B.; Kovalenko, A., The extrinsic cell death pathway and the elan mortel. Cell Death Differ 2008, 15, (10), 1533-1541.

24. Xiong, S. B.; Mu, T. Y.; Wang, G. W.; Jiang, X. J., Mitochondria-mediated apoptosis in mammals. Protein Cell 2014, 5, (10), 737-749.

25. Krelin, Y.; Zhang, L.; Kang, T. B.; Appel, E.; Kovalenko, A.; Wallach, D., Caspase-8 deficiency facilitates cellular transformation in vitro. Cell Death Differ 2008, 15, (9), 1350-1355.

26. Hitomi, J.; Katayama, T.; Eguchi, Y.; Kudo, T.; Taniguchi, M.; Koyama, Y.; Manabe, T.; Yamagishi, S.; Bando, Y.; Imaizumi, K.; Tsujimoto, Y.; Tohyama, M., Involvement of caspase-4 in endoplasmic reticulum stress-induced apoptosis and Abeta-induced cell death. The Journal of cell biology 2004, 165, (3), 347-56.

27. Obeng, E. A.; Boise, L. H., Caspase-12 and caspase- 4 are not required for caspase-dependent endoplasmic reticulum stress-induced apoptosis. J Biol Chem 2005, 280, (33), 29578-29587.

(C) 2015 by the authors; licensee MDPI, Basel, Switzerland. This article is an open access article distributed under the terms and conditions of the Creative Commons Attribution license (http://creativecommons.org/licenses/by/4.0/). 